\title{
A URBANIZAÇÃO DO OESTE PAULISTA E A FORMAÇÃO DE FEIÇÕES TECNOGÊNICAS
}

Érika Cristina Nesta SILVA

Marcel Bordin Galvão DIAS

João Osvaldo Rodrigues NUNES

Antonio Manoel dos Santos OLIVEIRA

Adriana Aparecida de OLIVEIRA

\begin{abstract}
RESUMO
Os processos de uso e ocupação da terra que originam e transformam os meios urbanos e rurais, exercidos pelas sociedades ao longo do tempo, são responsáveis, também, pela formação de feições tecnogênicas. Nos processos de urbanização, verifica-se que as sociedades alteram as características do meio físico-biótico (rocha-relevo-solo-clima-vegetação-fauna) para o desenvolvimento de diversas atividades. Em contrapartida, as atividades realizadas pelas sociedades são influenciadas pelas possibilidades advindas dos aspectos do meio físico-biótico. Ao se destacar o relevo, é imprescindível mencionar que sua apropriação ocorre de forma desigual e combinada, pois a sociedade, constituída por agentes sociais diversos, ocupa o relevo de forma diferenciada, ao mesmo tempo que suas ações fazem parte de um processo mais amplo, portanto, combinado, relacionado à lógica capitalista de produção do espaço. O mesmo procede no meio rural em que, especialmente no Oeste Paulista, as modificações na cobertura vegetal e, em consequência, em outros fatores do meio físico-biótico, como solos e relevo, ocorreram em decorrência da expansão das lavouras de café, algodão e do desenvolvimento da pecuária. No presente artigo são elucidadas questões relativas aos processos de expansão agrícola e urbanização e suas relações com formações tecnogênicas no Oeste Paulista, cuja origem, nas fases iniciais dessa ocupação, credita-se às erosões intensificadas pela ação da sociedade e consequentes deposições de sedimentos em áreas de fundos de vale. Destaque é dado para um estudo na região leste da cidade de Presidente Prudente - SP, apresentando aspectos sobre a expansão urbana e descrevendo formações de feições tecnogênicas, bem como sua evolução. Por fim, reforça-se que para compreender as feições tecnogênicas há a necessidade de conhecimento ampliado acerca da relação sociedade-natureza a partir de procedimentos que incluem visualizações em campo, em fotografias aéreas de diferentes períodos e retrospectiva acerca dos processos de uso e ocupação da terra.
\end{abstract}

Palavras-chave: Formações tecnogênicas; Uso e ocupação da terra; Oeste paulista; Presidente Prudente - SP.

\section{ABSTRACT}

URBANIZATION IN THE WEST OF SÃO PAULO STATE AND THE FORMATION OF TECHNOGENIC FEATURES. The processes of land use and occupation, which develop and transform urban and rural environments and are carried out by societies over time, are also responsible for the formation of technogenic features. During urbanization, societies change the characteristics of the physicalbiotic environment (rock-relief-soil-climate-vegetation-fauna) for the development of several activities. On the other hand, the activities carried out by the societies are influenced by the possibilities arising from the physical-biotic aspects. Regarding the 
relief, it is important to mention that it is affected in an uneven and differentiated way by society, which is constituted by several social agents and whose actions are part of an extensive process combined and related to the capitalist logic of urban space production. The same happens in rural areas where, especially in the west of São Paulo State (Brazil), changes in vegetation cover and, consequently, in other features of the biotic and physical environment, such as soil and relief, occurred as a result of the expansion of coffee and cotton plantations and livestock farming. This paper answers questions related to the processes of agricultural expansion, urbanization, and their relationship with technogenic formations in the west of São Paulo. In the initial phases of this occupation these formations are related to the erosion intensified by the action of society and to consequent deposition of sediments on valley bottoms. A study was conducted in the east part of the city of Presidente Prudente - SP, showing aspects of urban expansion and describing the formation and evolution of technogenic features. Therefore, for understanding technogenic features, a comprehensive knowledge of the relationship between society and nature is required, based on procedures including field and visualization of aerial photographs from different periods and a retrospective analysis of land use and occupation.

Keywords: Technogenic formations; Land use and occupation; West of São Paulo State (Brazil); Presidente Prudente - SP.

\section{INTRODUÇÃO}

As áreas urbanas estruturam-se a partir da modificação e apropriação dos compartimentos do relevo, dos solos e da estrutura geológica devido à inserção de formas artificiais, como as edificações e os equipamentos urbanos, os arruamentos e a pavimentação asfáltica, a canalização dos cursos d'água, que por sua vez alteram a dinâmica ambiental local, modificando as formas, os materiais e os processos ocorrentes.

A magnitude e os efeitos das intervenções humanas nestas localidades dependem, primeiramente, da natureza da intervenção e das características ambientais do local no qual se desenvolvem. Secundariamente, estas possuem um forte componente escalar, de forma que não se restringem apenas ao nível do local, podendo acarretar mudanças em diversas partes do meio físico, além do local da intervenção.

O relevo é alvo das modificações impressas pela urbanização. A ocupação dos compartimentos geomorfológicos (topos, vertentes e fundos de vale) é, por vezes, acompanhada por obras de terraplanagem, aterramento e escavação, destinadas a adequar a superfície para a construção de edificações, instalação da rede sanitária e pavimentação asfáltica, eliminando ou criando novas feições, condicionantes da dinâmica superficial e dos processos geomorfológicos (erosão-transporte-deposição).
Deste modo, a ação humana no ambiente produz efeitos diversos, especialmente em áreas urbanas, nas quais estes se ampliam e diversificam. Dentre os efeitos, tem-se a formação dos depósitos e terrenos tecnogênicos, materiais e formas resultantes das intervenções humanas sobre o meio natural, modificando-o de acordo com suas necessidades e possibilidades de intervenção, tanto do ponto de vista das potencialidades do meio físico quanto da disponibilidade de recursos e técnicas para as intervenções.

Sob essa perspectiva, vários pesquisadores brasileiros têm se debruçado sobre a temática dos depósitos e relevos tecnogênicos, desenvolvendo estudos no intuito de compreender a gênese destes materiais e formas, a exemplo das planícies e terraços tecnogênicos, e sua relação com as intervenções humanas desenvolvidas durante a ocupação e uso da terra, o que se denomina abordagem geotecnogênica. Tal abordagem pressupõe a caracterização ambiental e o resgate do histórico de uso e ocupação da área, objetivando reconstituir as condições anteriores à ocupação humana e as influências desta sobre a dinâmica da paisagem.

No presente texto buscou-se, inicialmente, resgatar o histórico de ocupação do Oeste Paulista, destacando-se as modificações ocorridas nas dinâmicas naturais a partir da ocupação e uso da terra, em especial, pelas atividades agropecuárias. Posteriormente, fez-se uma revisão a respeito das implicações da urbanização sobre o relevo, em especial no que tange os materiais, processos e for- 
mas. Finalizando, apresenta-se um estudo de caso realizado na cidade de Presidente Prudente-SP, que faz parte da tese de doutorado elaborada por SILVA (2017), destacando para o setor leste da área urbana, o histórico de ocupação da área e sua correlação com a gênese das feições tecnogênicas.

\section{HISTÓRICO DE OCUPAÇÃO DO OESTE PAULISTA}

A partir da colonização europeia, há cerca de 150 anos, as condições naturais foram alteradas de forma radicalmente intensa pelos fatores antrópicos, iniciados pelo extenso desmatamento, a ferro e fogo, conforme DEAN (2004). Em poucas dezenas de anos, a vegetação primitiva foi eliminada drasticamente e a terra foi submetida a manejos do solo até então inexistentes, processos antrópicos incomparáveis a quaisquer processos naturais anteriores.

Segundo BRANNSTROM (1998), um encadeamento de fatores concorreu para a rápida colonização do interior do estado de São Paulo, desde terras estrangeiras, centros de poder capitalista da época, até o mais distante rincão do oeste paulista: a expansão do consumo e a crescente importação do café pela Europa e pela América do Norte; o aumento dos capitais dos fazendeiros brasileiros que financiaram a construção de ferrovias; as imigrações de europeus e asiáticos para trabalharem nas lavouras, assim como de nordestinos.

MONBEIG (1984) afirma: "Desde o seu início, a marcha para oeste foi um episódio da expansão da civilização capitalista, nas duas margens do Atlântico. Ambas não cessaram de ser solidárias". Mas além do grande impulso inicial dado pelo café (PICCHIA 1927), também devem ser considerados nessa expansão econômica o cultivo do algodão e o desenvolvimento da pecuária. Os plantadores de algodão também recebiam importantes subsídios do governo para o desenvolvimento de novas variedades e também para atender a oferta de mão de obra, principalmente de imigrantes nordestinos, para o café (BRANNSTROM 1998).

Embora a história do uso da terra não tenha sido a mesma em todo o Planalto Ocidental Paulista, com áreas de usos predominantes diferenciados, de grandes pastagens, culturas de café e algodão, o desmatamento foi comum a todas elas. MONBEIG (1984) acompanhou a marcha pioneira do povoamento do interior paulista de 1937 a 1949 , e documentou-a em sua tese de doutorado à Sorbone (Paris, França), defendida em 1950, destacandose como uma das mais importantes testemunhas da transformação do interior paulista. Na década de 1930, o assim chamado sertão paulista, como grande espaço contínuo, já se restringia a uma faixa de cem a duzentos quilômetros ao longo do rio Paraná (MONBEIG 1984).

Segundo BRANNSTROM \& OLIVEIRA (2000) o uso extensivo do solo iniciou sua marcha decisiva no Planalto Ocidental Paulista entre 1880 e 1910, comandada pelos cafeicultores como prosseguimento do processo de ocupação de terras por café que, iniciado no estado do Rio de Janeiro, avançou pelo Vale do Paraíba, já no estado paulista, e se dirigiu para o oeste do estado de São Paulo.

As queimadas iniciadas no século XIX (FLORENCE 1977) em expedições ao interior, se sucederam extensas e persistentes ao longo dos primeiros anos do século XX para dar lugar ao café, algodão, amendoim e pastagens, eliminando de forma radical as coberturas vegetais florestais. Nos anos de 1960 a vasta região do Planalto Ocidental Paulista já se encontrava quase que totalmente desnudada.

A esta primeira alteração ambiental promovida pela colonização europeia, sucederam-se outras alterações dentre as quais podem ser destacadas aquelas provocadas pelo processo de urbanização desde os anos 1960, a substituição de culturas agrícolas por outras e pela pecuária, a construção de barragens de grande porte nos principais rios que delimitam o Planalto - o Grande, o Paraná e o Paranapanema - e o que o atravessa - o Tietê - que transformaram seus principais cursos d'água em lagos artificiais, entre os anos de 1960 e 1990.

Entretanto, deve-se reconhecer o grau maior de intensidade de transformação ambiental da primeira intervenção extensiva (desmatamento) sobre as seguintes, pelo simples fato de que, em poucos anos, foi praticamente suprimido o componente biótico natural do ambiente e introduzido o componente cultural trazido pelos colonizadores.

Em cerca de 50 anos a região praticamente perdeu um dos componentes do ambiente natural: o meio biótico, alterando profundamente o balanço hídrico. Depois de milhares de anos de uma dinâmica natural dos processos geológicos superficiais, a eliminação de um dos principais fatores condicionantes dessa dinâmica alterou de forma radical o balanço hídrico e o comportamento das águas no escoamento e infiltração nos terrenos 
desnudos. Esse desequilíbrio hídrico passou a promover alterações na cobertura pedológica que, em geral, é muito sensível à circulação hídrica tanto em superfície quanto em subsuperfície, devido à natureza arenosa das formações do Grupo Bauru. Solos altamente erodíveis passaram a sofrer entalhes erosivos, com a instalação de sulcos e ravinas, além do surgimento de voçorocas nas cabeceiras das nascentes dos cursos d'água, cujos sedimentos colmatam os fundos de vale de primeira ordem formando os depósitos tecnogênicos (OLIVEIRA \& QUEIROZ NETO 1994).

\section{URBANIZAÇÃO E APROPRIAÇÃO DO RELEVO}

Ao longo do tempo, as diferentes civilizações desenvolveram-se a partir da transformação dos recursos naturais, produzindo os bens necessários à sua existência ao mesmo tempo em que imprimiam modificações às condições naturais originais. A evolução das forças produtivas e a complexificação das sociedades responderam pelo avanço na apropriação e transformação da natureza.

Conforme CASSETI (1991), concomitantemente a esta apropriação, iniciou-se um processo de produção da natureza, no qual a história social se coloca como uma continuação da própria história natural.

A relação de apropriação e transformação estabelecida entre sociedade e natureza é condicionada por um conjunto de fatores, responsáveis por estabelecer distintos modos de intervenção, resultando em paisagens com fisionomias, dinâmicas e funcionalidades diversas. Neste sentido, a análise dos condicionantes do meio físico-biótico (rocha-relevo-solo-climavegetação-fauna) mostra-se relevante ao propiciar o entendimento da fisiologia da paisagem e o modo como os aspectos fisiográficos interferem no desenvolvimento das atividades humanas, especialmente nas cidades.

A produção da cidade perpassa por várias esferas de análise: a política, a econômica, a cultural, a social e a ambiental. O sítio urbano está assentado sobre um relevo, que é apropriado de forma desigual e combinada (NUNES 2002).

Em relação à ocupação das formas de relevo, a sociedade composta pelos agentes sociais que lhe dão dinamicidade, edifica suas realizações materiais (estradas, prédios, canalizações de córregos etc.), que se transformam nas rugosidades temporo-espaciais (SANTOS 1996). Ou seja, a produção do espaço físico das cidades é, ao mesmo tempo, a produção de natureza transformada e modificada pelo jogo de interesses públicos e privados que constroem, destroem e reconstroem novos espaços sociais (NUNES 2002).

$\mathrm{O}$ advento das cidades transformou os ambientes de acordo com os princípios da lógica capitalista de produção do espaço geográfico, criando espaços desiguais e fragmentados. Os desequilíbrios provocados na dinâmica ambiental urbana ampliam-se e diversificam-se mediante a complexidade e dinamicidade do espaço urbano, especialmente em áreas densamente urbanizadas.

Assim, conforme descreve SMITH (1988, p. 87-88):

A reprodução da vida material fica totalmente dependente da produção do valor excedente. Para este fim, o capital se volta para a superficie do solo em busca dos recursos materiais; a natureza torna-se um meio universal de produção, de modo que ela não somente provê o sujeito, o objeto e os instrumentos de produção, mas ela é em sua totalidade um acessório para o processo de produção.

O espaço urbano coloca-se como a materialidade da ação humana sobre a natureza, através do trabalho, adaptando o meio natural em consonância com as especificidades da cultura e da organização socioespacial vigente, criando um verdadeiro habitat do homem. A cidade é, assim, fruto da construção humana, produto social ou projeção do trabalho sobre natureza, caracterizada por espaços distintos e com funções diferenciadas.

Conforme NUNES (2002), a apropriação da chamada natureza primária em segunda natureza ou natureza transformada se intensificou a partir do processo de urbanização, precedido de uma intensa industrialização, que culminou na chamada sociedade urbana.

No caso brasileiro, o processo de urbanização teve como força motriz a indústria nascente a partir da conversão do capital agrícola em capital industrial, transformando as relações produtivas e, em especial, a relação campo-cidade. A partir deste momento, inicia-se um "esvaziamento" do meio rural e um vertiginoso crescimento das cidades, especialmente dos médios centros urbanos, o que resultou em inúmeros impactos ambientais.

A urbanização brasileira foi caracterizada por um crescimento das cidades, com raras exceções, desacompanhado da instalação de estrutura urbana 
consonante e adequada as dinâmicas da natureza. Dada à inobservância desses aspectos naturais, as alterações promovidas pela interferência humana acabaram por desencadear diversos problemas ambientais, tais como a poluição do ar e das águas (superficiais e subterrâneas) e a contaminação/ degradação dos solos, sobretudo nas áreas densamente urbanizadas.

Assim, os diversos estudos ambientais desenvolvidos em áreas urbanas atentaram-se, prioritariamente, para a identificação dos impactos decorrentes da inobservância das capacidades e fragilidades do meio natural, elaborando diagnósticos e propondo medidas mitigadoras no intuito de restabelecer o equilíbrio natural.

Dentre os impactos, merecem destaque aqueles relacionados à alteração da hidrodinâmica:

A impermeabilização de superfícies respondeu pela redução substancial da infiltração, com consequente acréscimo do escoamento superficial. Diante disso, temse a redução do abastecimento do lençol freático, o que implica desperenização dos cursos d'água, ao mesmo tempo em que responde por suas descargas excepcionais (fluxo torrencial) no período das chuvas (CASSETI 1991, p. 114).

O escoamento superficial intensificado pela ampliação da impermeabilização superficial e inexistência de estruturas de drenagem adequadamente dimensionadas, respondem pela incrementação das atividades erosivas, manifestadas pela formação de novos processos erosivos e intensificação daqueles que se manifestaram quando do desmatamento, na forma de ravinas e voçorocas, atingindo especialmente as áreas periurbanas.

A dinâmica sedimentológica é igualmente impactada pela urbanização. As alterações no aporte de sedimentos retirados, transportados e depositados pelo trabalho das águas superficiais são resultantes das diversas intervenções antrópicas, a exemplo da inserção de formas artificiais, como as edificações e os equipamentos urbanos, a pavimentação e compactação do solo, a canalização dos cursos d'água e a retirada da cobertura vegetal original.

Assim, o que se observa é a reconfiguração da dinâmica hidrossedimentológica nos diferentes compartimentos do relevo (topos, vertentes e fundos de vale) ocupados pela urbanização. Tais compartimentos, de acordo com suas características morfológicas e morfométricas, interferem no ordenamento territorial urbano atuando como facilitadores ou entraves à ocupação urbana.

O relevo merece destaque por influenciar significativamente no uso e ocupação das terras, a partir da existência de diferentes feições geomorfológicas, produto da combinação de forças endógenas e exógenas, tornando-se peçachave no processo de urbanização, responsável por direcionar as frentes de expansão urbana, e também alvo das intervenções antrópicas destinadas a adequá-lo ao uso e ocupação, como cortes, aterros, escavações, terraplanagens, que resultam na modificação dos materiais, processos e formas ocorrentes no ambiente urbano.

Assim, os efeitos das intervenções antrópicas nas cidades são cumulativos e diversificados, expressando-se de variadas formas, como, por exemplo, por meio da configuração do clima urbano, das alterações na dinâmica natural dos rios, com a consequente transformação dos processos atuantes, e da criação dos depósitos tecnogênicos, conforme proposição e definição de CHEMEKOV (1983).

De acordo com NUNES et al. (2016), no caso das cidades e de sua geração de depósitos tecnogênicos, é importante que se compreendam as formas de produção e de consumo do espaço urbano. Devem ser enfocados, assim, tanto os agentes detentores do poder de decisão e de controle dos meios de produção, bem como o entendimento da dinâmica da natureza nas suas diversas interfaces (geológica, geomorfológica, climática, vegetacional, etc.).

Dada a magnitude destes efeitos, foi proposta a criação de um novo período geológico, o Quinário, e sua época correspondente, o Tecnógeno (TER-STEPANIAN 1988). Assim, o Holoceno seria considerado como uma época de transição entre os períodos Quaternário e o Quinário. Os estudos desenvolvidos no âmbito do Tecnógeno concentram-se na análise dos produtos gerados (direta ou indiretamente) pelas atividades humanas, bem como seus respectivos processos geradores. Outra proposta de inclusão de uma época na escala do tempo geológico que tem sido bastante discutida recentemente, no cenário nacional e internacional, é a relativa ao Antropoceno, conceito originalmente proposto por CRUTZEN \& STOERMER (2000), o qual diz respeito a uma época geológica cuja principal referência é a ação humana enquanto modificadora dos ambientes da superfície e atmosfera terrestre. 
A partir das considerações acerca das alterações promovidas pela ação da sociedade na criação e constante reelaboração do meio físico nos espaços urbanos, a presente contribuição apresenta o estudo das deposições tecnogênicas na cidade de Presidente Prudente - SP, bem como o advento de novas formas geomorfológicas de origem antrópica, especialmente ao se considerar a escala espacial local.

\section{A OCUPAÇÃO URBANA DE PRESIDENTE PRUDENTE - SP E AS FORMAÇÕES TECNOGÊNICAS}

O município de Presidente Prudente (Figura 1) localiza-se na morfoescultura do Planalto Ocidental Paulista, dentro da morfoestrutura da Bacia Sedimentar do Paraná, especificamente no extremo oeste do estado de São Paulo, Brasil (Figura 2).

A ocupação do Planalto Ocidental Paulista e a implantação/ampliação de estradas de ferro para o interior, visando o transporte de pessoas e escoamento de produção, foram condicionantes para o surgimento e crescimento inicial da cidade de Presidente Prudente. O município foi fundado em 1917, quando iniciou-se a derrubada da mata em frente ao marco onde passaria a estrada de ferro Sorocabana, inaugurada em 1920, na área do espigão central, principal divisor de águas do município. Assim, a ocupação urbana inicia-se, principalmente, nos compartimentos dos topos das colinas suavemente ondulados para, posteriormente, alcançar os demais compartimentos (vertentes e fundos de vale).

O crescimento da cidade de Presidente Prudente impulsionou alterações nas características físico-bióticas no espaço urbano, conforme pode ser visto na figura 3, que mostra a expansão urbana sobre os diferentes compartimentos do relevo.

As modificações ocasionadas nos aspectos físicos da paisagem, como cursos d'água assoreados e soterrados, alterações no relevo (como cortes e novas feições erosivas), destacadas em SILVA (2009, 2012, 2017), são em grande parte condicionadas por processos como os decorrentes da ampliação da impermeabilização superficial e retirada da cobertura vegetal primária, reduzindo a infiltração de água no solo e intensificando, em volume e velocidade, o escoamento superficial. Como consequência, intensificaram-se os processos erosivos, especialmente os lineares (sulcos, ravinas e voçorocas), carreando maior volume de sedimentos para as áreas de fundos de vale. Junto com esses sedimentos outros materiais foram depositados, em decorrência do avanço do processo de urbanização e aumento do uso de materiais artificiais. Entre estes materiais constam os advindos da construção

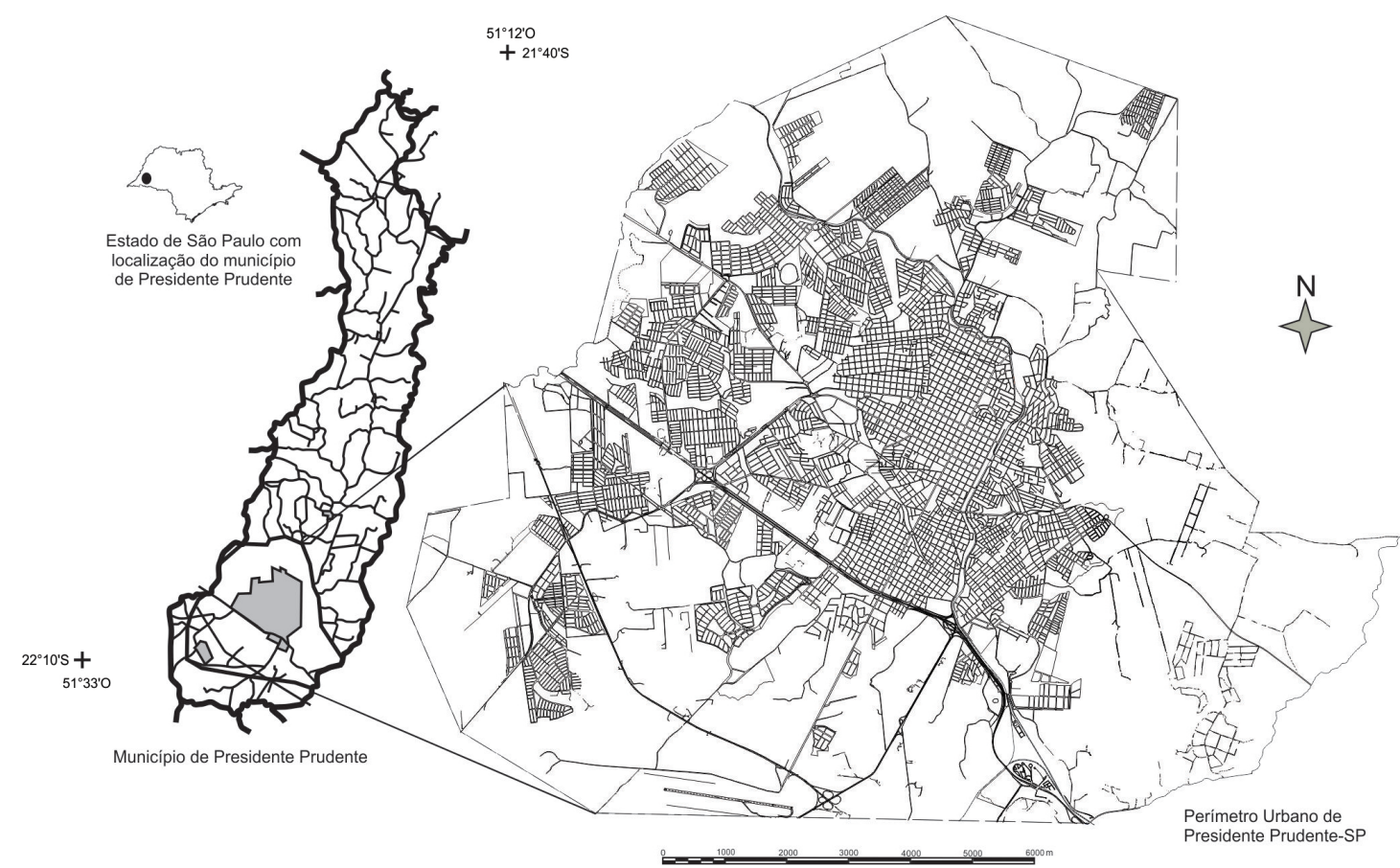

FIGURA 1 - Mapa de localização da área urbana de Presidente Prudente, São Paulo, Brasil. Fonte: Adaptado de SILVA (2017). 


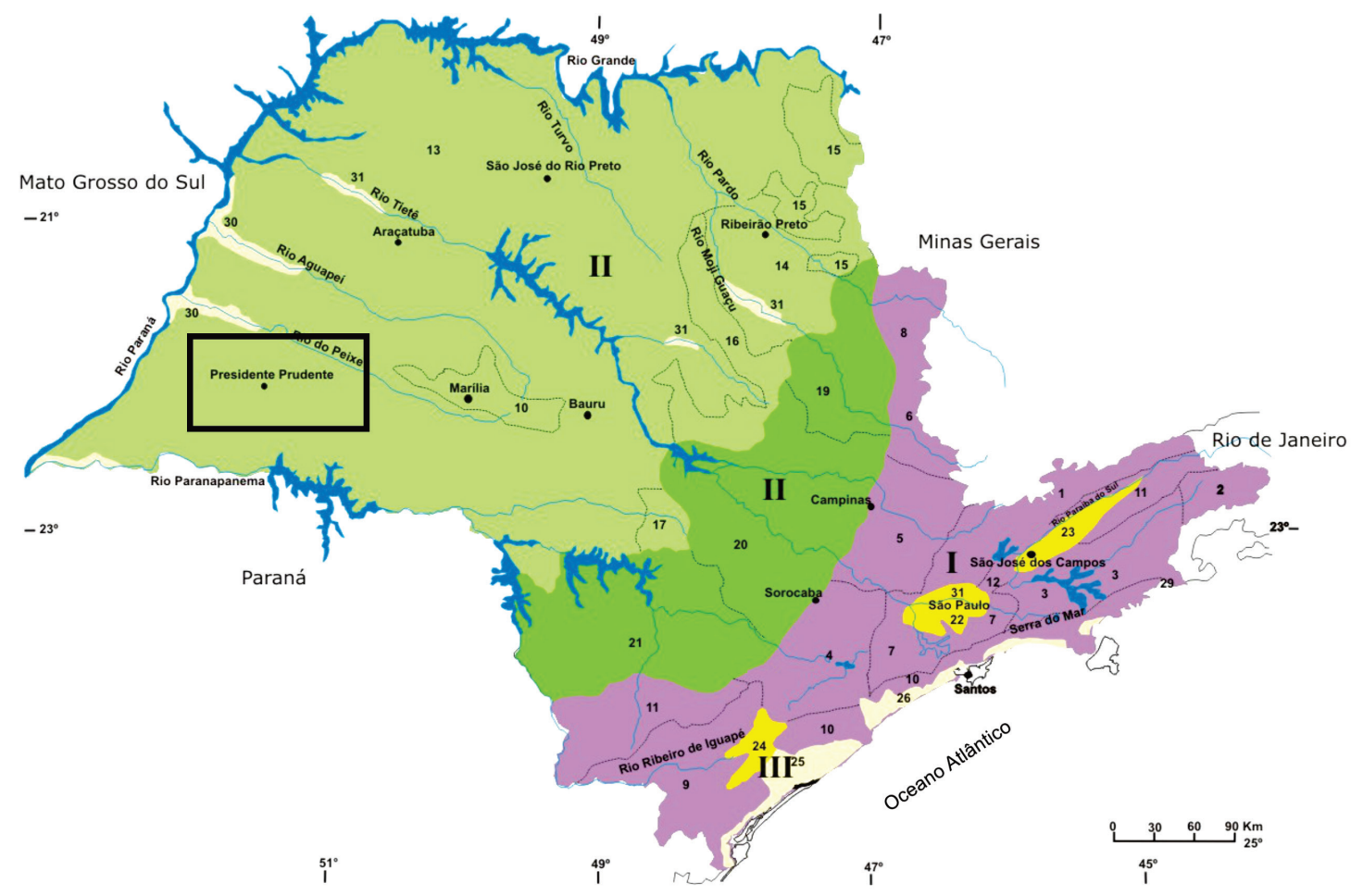

I - CINTURÃO OROGENICO DO ATLÅNTICO

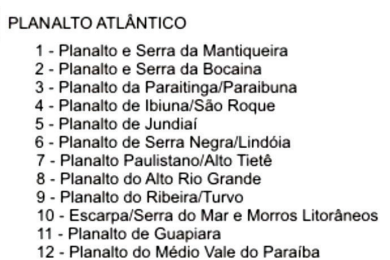

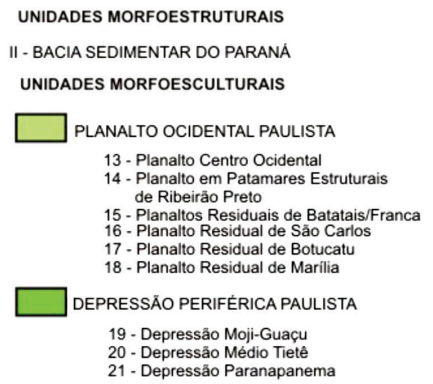

III - BACIAS SEDIMENTARES CENOZOICAS

2 - Planalto de São Paulo - Depressão do Médio Paraiba PLANICIES LITORÃNEAS E FLUVIAIS 25 - Iguapé/Cananéia 26 - Praia Grande/lperoib 27 - Santista 29 - Litoral Norte 30 - Rio Paraná 31 - Diversos

Fonte: Ross e Moroz (1997)

FIGURA 2 - Mapa Geomorfológico do Estado de São Paulo. Destaque para a localização do município de Presidente Prudente-SP. Fonte: ROSS \& MOROZ (1996).

civil, que também foram carreados, em fragmentos junto a sedimentos, para os fundos de vale, alterando os níveis de base locais.

SILVA $(2009,2012,2017)$ amostrou diversos fundos de vale, especialmente em áreas periurbanas, com quantidade expressiva de sedimentos e materiais manufaturados depositados, definindo-os como deposições tecnogênicas. Como exemplo de volume dessas deposições (Figura 4), a partir da descrição das camadas presentes em sondagens realizadas, chegou-se ao cálculo aproximado do volume, para a área do fundo de vale situada na Vila Nova Prudente, de cerca de $10.000 \mathrm{~m}^{3}$, ao considerar a presença de fragmentos de carvão, possivelmente relacionada aos processos de queimada durante à derrubada da mata para fins agrícolas, e ao valor de $7.710 \mathrm{~m}^{3}$, para a deposição, mais super- ficial, de sedimentos com materiais manufaturados presentes, decorrentes da instalação do loteamento e da proximidade com uma antiga área de disposição de resíduos sólidos domésticos (Figura 5), situada em uma nascente.

Além da Vila Nova Prudente, já foram estudados utilizando-se a abordagem geotecnogênica outros bairros e setores de Presidente Prudente, a exemplo dos trabalhos desenvolvidos por GODOY et al. (2002), NUNES (2002), PIRES et al. (2006), SILVA (2011) e SILVA (2009, 2012, 2017).

O setor leste de Presidente Prudente pode ser considerado um bom exemplo de área que apresenta feições geomorfológicas e depósitos sedimentares de origem tecnogênica na cidade, em decorrência da presença de bairros bastante antigos, a exemplo da Vila Marcondes, que surge 

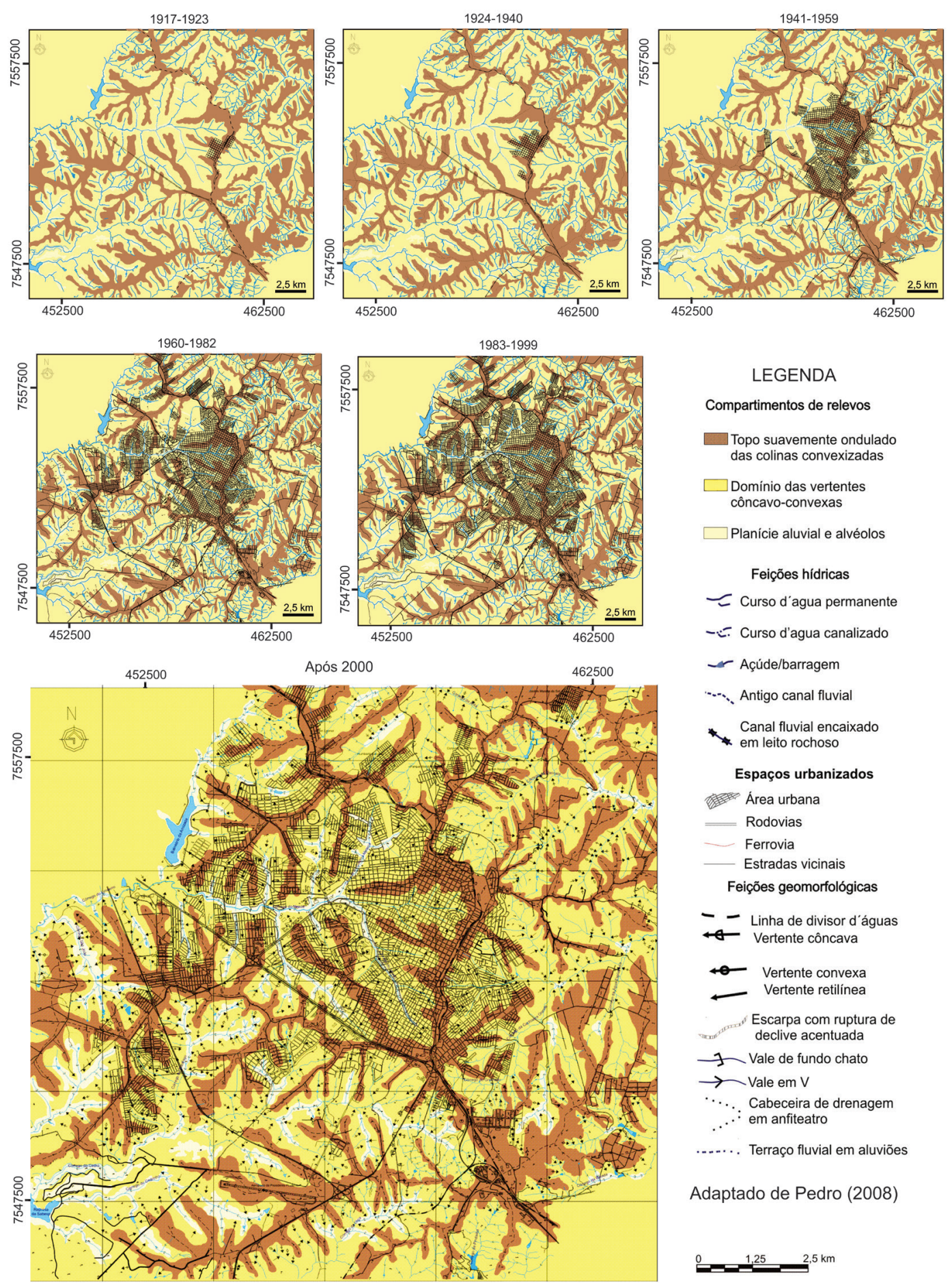

Adaptado de Pedro (2008)

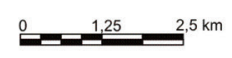

FIGURA 3 - Expansão territorial urbana da cidade de Presidente Prudente-SP sobre as formas de relevo, no período de 1917 a 2000. Fonte: Adaptado de PEDRO (2008).

antes da fundação do município, com o objetivo de acolher os compradores de terra que negociavam com a Companhia Marcondes (ABREU 1972).

Localizado imediatamente a leste da linha férrea, este setor apresenta características particulares ao ser comparado com o restante do espaço urbano da cidade, como a maior presença de setores considerados de exclusão social, juntamente com o setor norte (SPOSITO 2003). Outro aspecto, além do adensamento de áreas de 


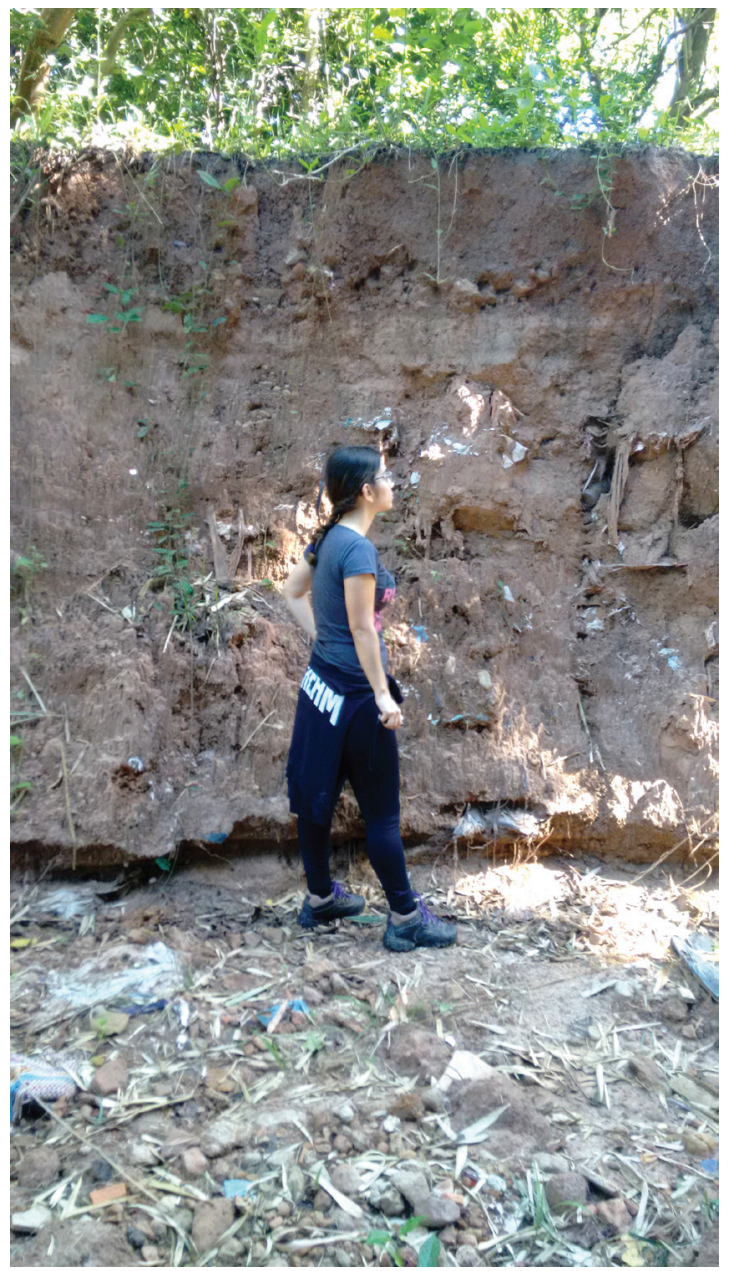
Nova Prudente, com camadas expostas em decorrência da instalação de uma feição erosiva na área da planície. Observam-se materiais tecnogênicos, especialmente plásticos e tecidos possivelmente transportados de uma antiga área de deposição de resíduos sólidos a montante, pelo fluxo superficial de água. Fonte: Adaptado de SILVA (2017).

maiores declividades (Figura 6) em comparação ao setor oeste, é a presença de colinas menores, topos convexos e fundos de vale encaixados, com pouca ou nenhuma presença de planícies aluviais, expondo os arenitos da Formação Adamantina (Grupo Bauru).

Ao observar-se a expansão urbana de Presidente Prudente, nota-se que o setor leste teve menor crescimento em relação ao setor oeste, devido a fatores condicionantes como as características geomorfológicas (declividades acentuadas das vertentes, por exemplo), que exigem maior dispêndio de recursos de engenharia para garantir a segurança das habitações, com a necessidade de construção

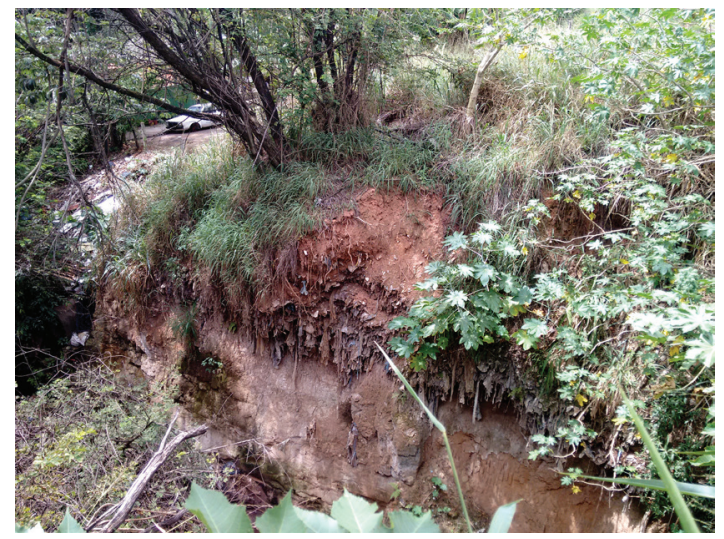

FIGURA 5 - Antiga área de deposição de resíduos sólidos localizada a montante da planície na Vila Nova Prudente (provável fonte de materiais e sedimentos). Fonte: Adaptado de SILVA (2017).

de muros de arrimo, sistemas de bombeamento de águas e esgoto, etc.

Em parte do setor leste, destaca-se como área de interesse para compreensão das formações tecnogênicas o fundo de vale com curso d'água canalizado de forma fechada, localizado sob a avenida Tancredo Neves, bem como as áreas adjacentes. Neste trecho foi possível identificar diferentes alterações no ambiente físico ao longo dos anos (SILVA 2017). Para isso, foi realizada a reconstituição de aspectos da paisagem por meio de fotografias aéreas de diferentes períodos, com escalas de 1:25.000 (1962 e 1995), e de 1:20.000 (1978), e de imagem do Google Earth (2016) (Figura 7), trabalhos de campo para observação das paisagens e reconstituição dos processos históricos de uso e ocupação da terra, bem como o registro das áreas de antigas deposições de resíduos sólidos domésticos (MAZZINI 1997).

A partir da interpretação de fotografias aéreas reconheceu-se que já em 1962 a área encontrava-se bastante alterada, especialmente no que diz respeito à supressão da mata, mesmo nas adjacências dos cursos d'água, o que intensificou prováveis processos de assoreamento dos canais nesses locais.

Nas fotografias dos períodos seguintes (1978 e 1995), nota-se que as áreas dos canais de drenagem de primeira ordem encontram-se urbanizadas, com presença de arruamentos sobre elas, principalmente no sentido noroeste da área abrangida pelas fotografias aéreas.

No caso dos cursos d'água principais, que são afluentes do córrego do Gramado, foram realizadas obras de engenharia hidráulica com canalizações fechadas e abertas, alterando as características 


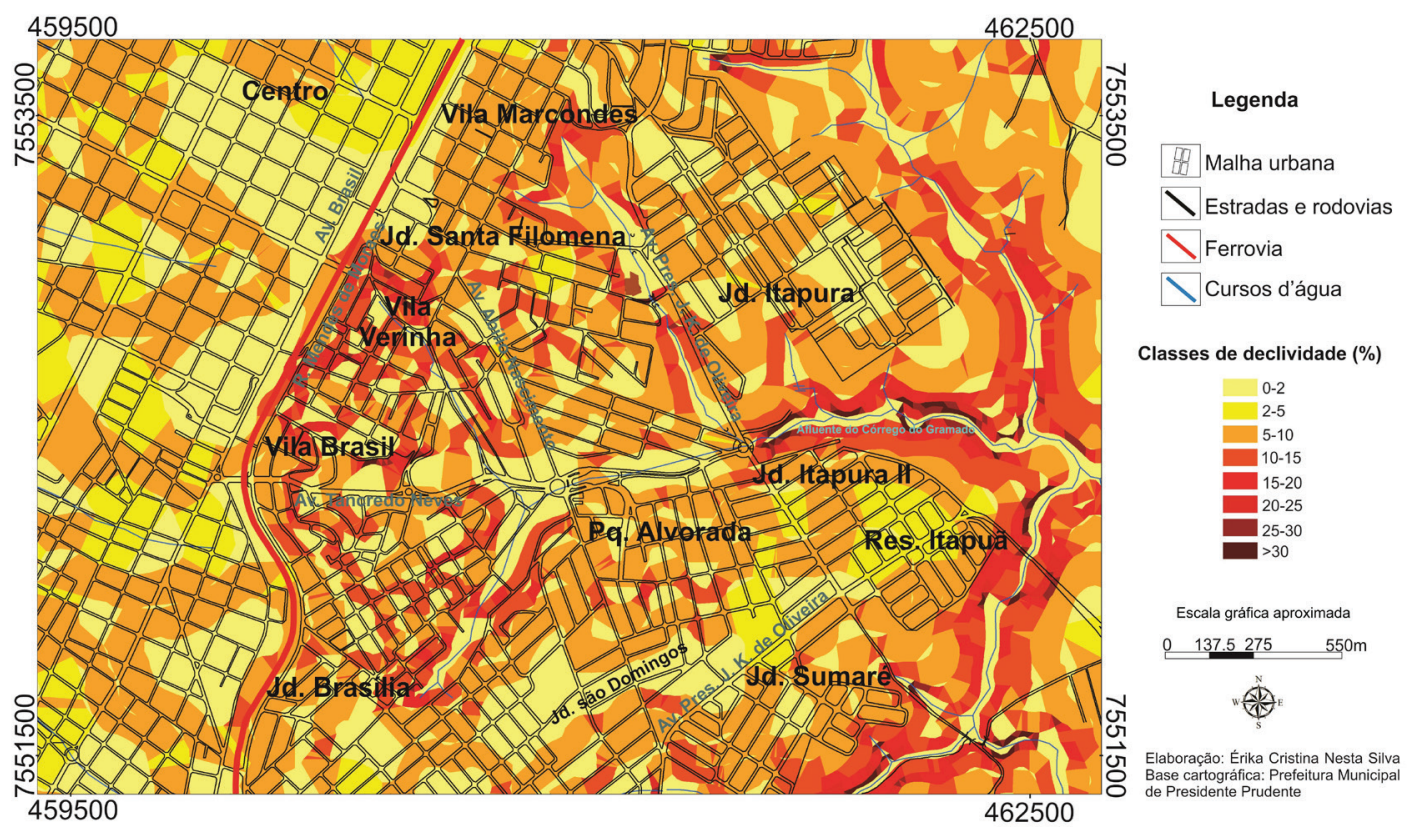

FIGURA 6 - Carta clinográfica de parte do setor leste de Presidente Prudente. Nota-se a diferença de declividade entre os setores leste e oeste, nas proximidades da estrada de ferro Alta Sorocabana. Fonte: Adaptado de SILVA (2017).

naturais dos leitos e talvegues dos cursos d'água, bem como o próprio processo de drenagem das águas que infiltram e escoam dos compartimentos das vertentes e topos das colinas próximas. Cabe observar que, em alguns trechos dos traçados originais de cursos d'água, os lotes delimitados apresentam vegetação arbórea, provavelmente residual do antigo fundo de vale. Esse processo de expansão urbana em áreas de extintos canais ocorre em diversas cidades, portanto, não é exclusivo de Presidente Prudente.

A presença de solo exposto e de feições erosivas nas fotografias aéreas é bem expressiva, especialmente nas proximidades dos cursos d'água no período de 1962 a 1978. Quanto à deposição de resíduos sólidos domésticos, conforme resgatado na literatura e observado nas fotografias aéreas, reconheceu-se que as áreas de antigas feições erosivas e fundos de vale eram áreas preferenciais para deposição, tanto no setor leste quanto norte da cidade. Essas deposições provavelmente sofreram e têm sofrido remobilizações para áreas cada vez mais a jusante nos canais de drenagem. Em alguns locais, como na Vila Marcondes, na antiga área de deposição de resíduos sólidos domésticos foi implantada uma praça. Observa-se a necessidade de reconhecimento dessas áreas para que seja evitada a instalação de loteamentos, visto a instabilidade do terreno, conforme destaca PELOGGIA (1998, p. 132-133):

Em sintese, as instabilidades relatadas em aterros urbanos permitem a definição de algumas caracteristicas gerais, quais sejam: 1) a alta mobilidade da massa escorregada; 2) o mecanismo de instabilização via de regra associado à geração de pressões neutras no maciço (lençol d'água empoleirado); 3) a independência da ruptura em relação à ocorrência de chuvas; 4) o alto potencial destrutivo dos escorregamentos, freqüentemente sob a forma de "corridas".

[...] Depósitos nos quais materiais de lixo (material "gárbico") são enterrados podem dar lugar: a) a subsidências das superficies dos terrenos; b) a riscos de explosões em função da geração de metano $e$ outros gases naturais sob condições anaeróbicas; c) à contaminação das águas subterrâneas com substâncias químicas.

Com relação ao aspecto destacado por PELOGGIA (1998) acerca da alta mobilidade da massa escorregada, faz sentido principalmente nos casos em que as deposições ocorrem em áreas de declividades acentuadas, como nas nascentes da Vila Marcondes (entre 15 e 20\% de declividade) e Vila Brasil (com declividade superior à 30\%). 

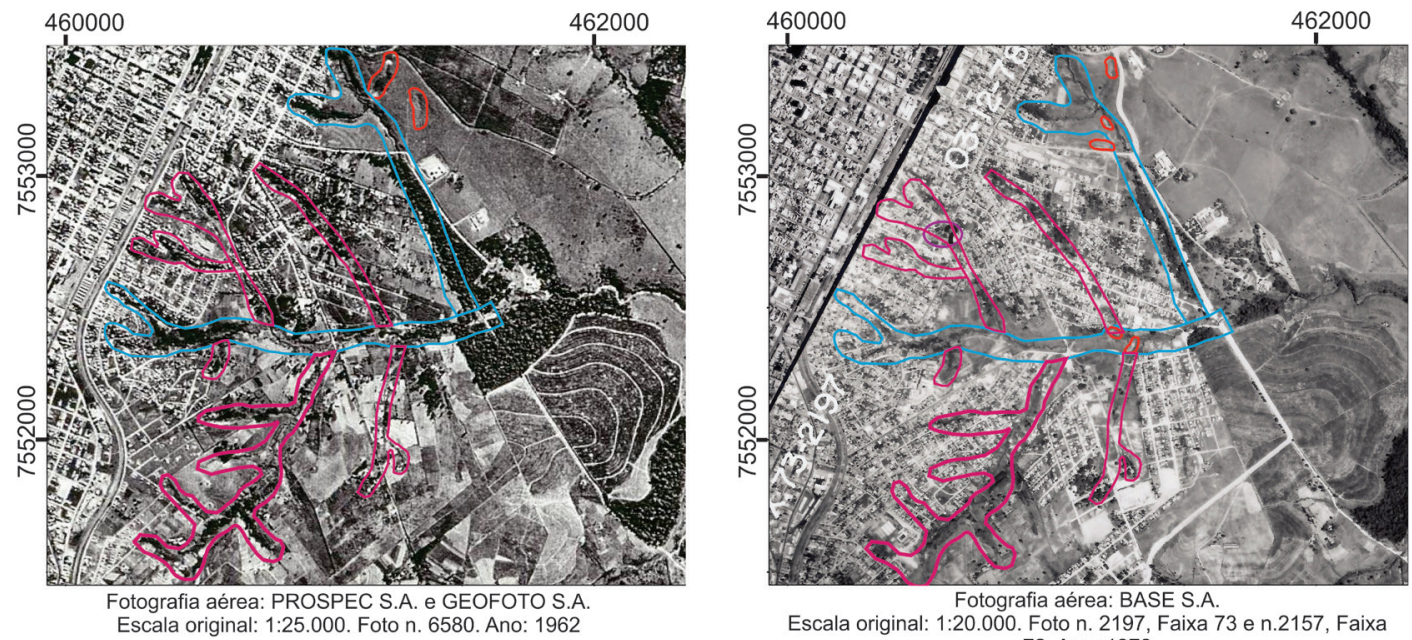

Escala original: 1:20.000. Foto n. 2197, Faixa 73 e n.2157, Faixa 72. Ano: 1978
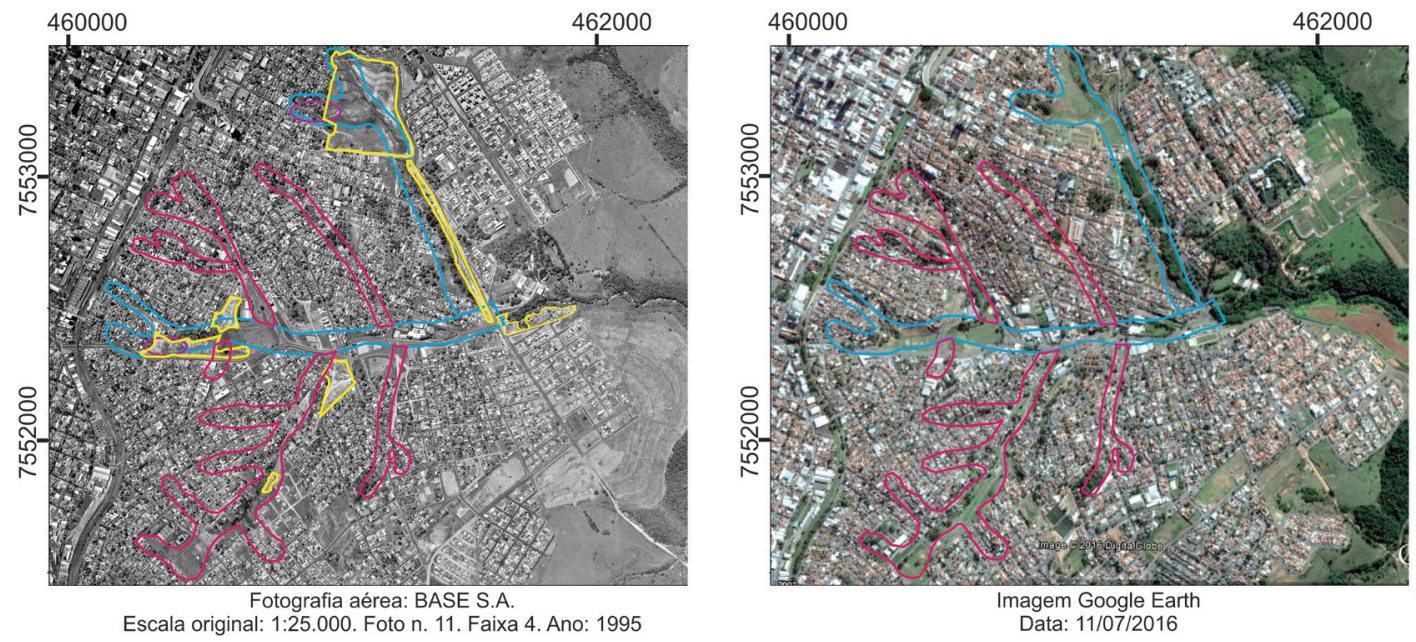

Escala original: 1:25.000. Foto n. 11. Faixa 4. Ano: 1995

Data: 11/07/2016

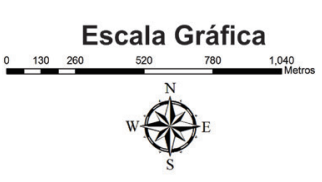

Elaboração: Érika Cristina Nesta Silva

FIGURA 7 - Modificação nas características físicas das paisagens em parte do setor leste de Presidente Prudente reconhecidas nas fotografias aéreas de 1962, 1978, 1995 e imagem do Google Earth de 2016. Fonte: Adaptado de SILVA (2017).

A partir dessas observações realizadas nas fotografias aéreas, foi possível reconhecer as formas e feições tecnogênicas e inseri-las na carta geomorfológica, que apresenta os compartimentos do relevo (Figura 8). Esse mapeamento permitiu identificar as áreas de terrenos tecnogênicos, conforme classificação de PELOGGIA et al. (2014), que foi revista e ampliada em PELOGGIA (2017). Como exemplo de terrenos tecnogênicos na área pesquisada tem-se:
1) terrenos tecnogênicos de agradação com presença de depósitos sedimentares induzidos aluviais (ou depósitos tecnogênicos induzidos de fundos de vale, conforme PELOGGIA 2017), nos cursos d'água e adjacências;

2) possíveis terrenos tecnogênicos de degradação, do tipo escavado, nos talvegues e taludes dos cursos d'água para implementação das canalizações;

3) terrenos tecnogênicos de degradação, do tipo erodido; 


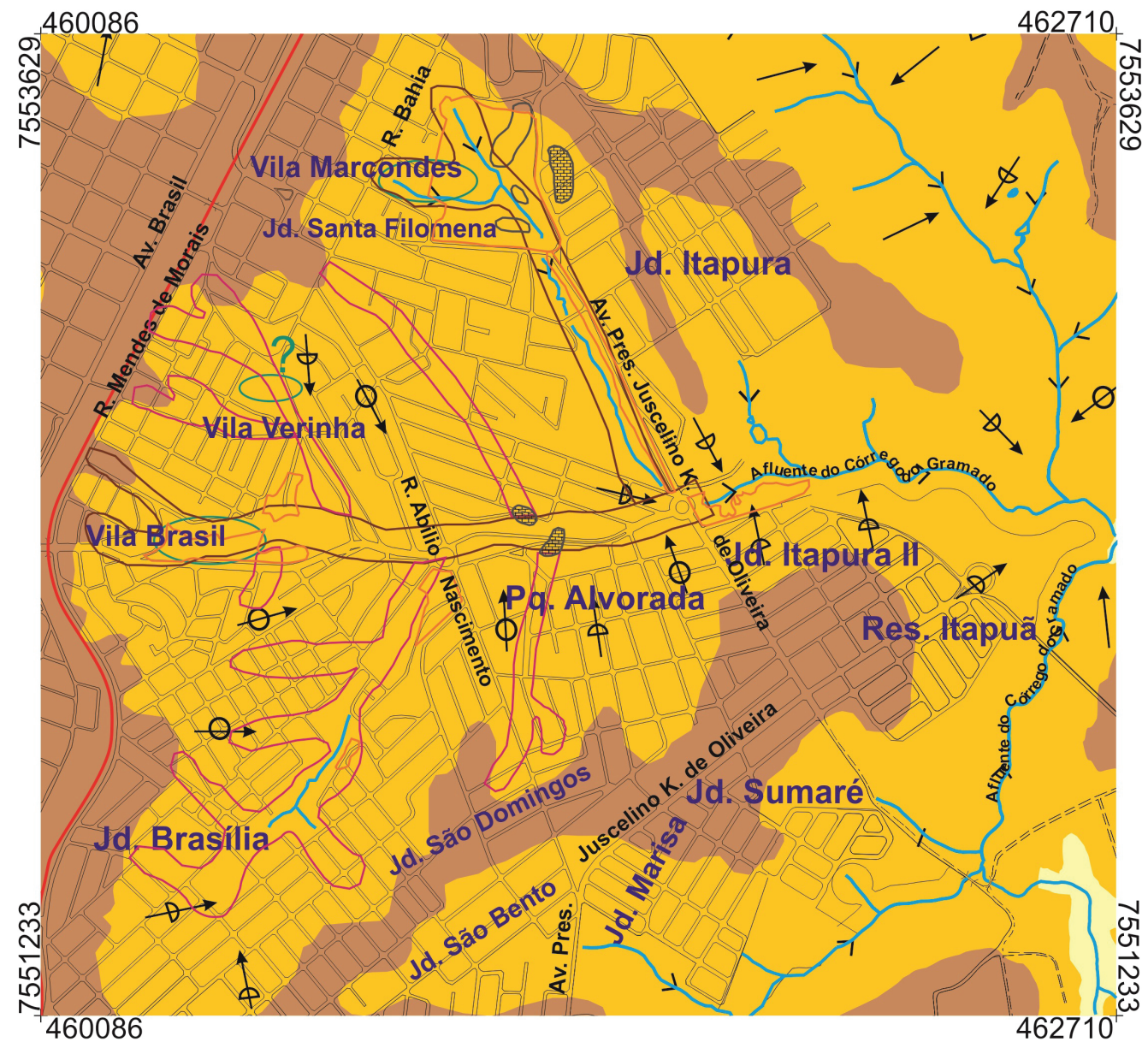

\section{LEGENDA}

COMPARTIMENTOS DE RELEVO

Topo suavemente ondulado das Colinas Convexizadas

Domínio das vertentes Côncavo-Convexas

Planícies aluviais e alvéolos

FEIÇÕES HÍDRICAS

C Curso d'agua permanente

Açúde/Barragem

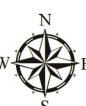

FEIÇÕES GEOMORFOLÓGICAS

- . - Linha de divisor d'aguas

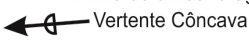

$\leftarrow$ Vertente Convexa

$\leftarrow$ Vertente Retilínea

$\rightarrow$ Vale em V

ESPAÇOS URBANIZADOS

Loteamento

Ferrovia

Estradas Vicinais
FEIÇÕES E FORMAS TECNOGÊNICAS

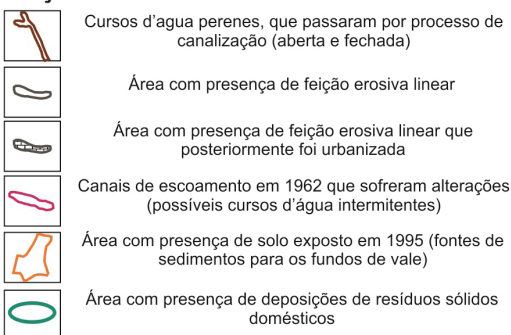

Adaptação do Mapa Geomorfológico do Perímetro Urbano de Presidente Prudente-SP (NUNES; FREIRE; PEREZ, 2006) com base cedida pela prefeitura (2010)

FIGURA 8 - Formas e feições tecnogênicas associadas aos compartimentos do relevo em parte do setor leste de Presidente Prudente - SP. Fonte: SILVA (2017).

4) terrenos tecnogênicos de agradação, em antigas feições erosivas com recobrimento com sedimentos e, em alguns casos, com deposições de resíduos sólidos domésticos (materiais úrbicos e, principalmente, gárbicos), conforme classificação presente em PELOGGIA (1996).

O exemplo apresentado, no qual constam as formações tecnogênicas, demonstra algumas características do processo de urbanização ocorrido em Presidente Prudente, especialmente nas primeiras décadas de sua história, quando as características naturais da paisagem não foram ou pouco foram consideradas durante a execução de loteamentos e demais obras. Resultou-se, portanto, na formação ora de feições erosivas, causando deposições tecnogênicas induzidas a jusante, especialmente 
nos fundos de vale, ora de deposições diretas e indiretas de materiais úrbicos e gárbicos, em grande parte em áreas inapropriadas, devido aos riscos de mobilização dos materiais depositados, riscos de explosões e de contaminação das águas superficiais e subsuperficiais.

Além disso, nota-se que parcela significativa dessas áreas de deposição tecnogênica encontram-se em loteamentos populares cujas pessoas vivem em situação intermediária (setores que, de acordo com os indicadores estabelecidos em SPOSITO (2003), obtiveram nota que não os enquadra em situação de inclusão e nem de exclusão social) e de exclusão social, o que pode agravar os problemas, sejam relativos aos vetores de doenças, ou de ordem geotécnica, decorrente da instabilidade dos materiais, como aponta PELOGGIA (1998).

\section{CONSIDERAÇÕES FINAIS}

Os depósitos tecnogênicos representam a materialização da ação humana sobre a superfície terrestre em diversas escalas de grandeza, seja de modo direto ou indireto. Este fato está diretamente relacionado ao tempo do Antropoceno, onde as ações humanas ao longo da história têm deixado marcas e feições "estratigráficas" representativas de uma nova época geológica.

Como já demostrado por OLIVEIRA (1994), na história de ocupação do Oeste Paulista, com especial destaque para a formação das áreas urbanas, a substituição da cobertura vegetal que protegia solos com classe textural arenosa, ocasionou de montante para jusante o desenvolvimento de intensos processos erosivos lineares e laminares, que ao transportar os sedimentos para os fundos de vales formaram grandes deposições de origem tecnogênica constituídas por materiais das mais diversas origens.

Conforme PELOGGIA et al. (2014), a cidade de Presidente Prudente é um dos tantos exemplos de como o processo de urbanização ao longo da história de ocupação do Oeste Paulista alterou tecnicamente as características do meio físico-biótico, formando terrenos tecnogênicos.

DIAS (2015) salienta que o desenvolvimento das técnicas e a complexificação das sociedades ampliaram a capacidade interventora sobre as dinâmicas da natureza, atribuindo-lhe o papel de agente geológico-geomorfológico. A magnitude e intensidade da ação humana sobre as dinâmicas da natureza variam no tempo-espaço, de acordo com os diversos arranjos socioambientais e o nível de desenvolvimento dos diferentes grupos sociais.
A formação de depósitos tecnogênicos e relevos tecnogênicos está intrinsecamente relacionada, visto que a existência de áreas de deposição tecnogênica pode alterar as características geomorfológicas do local, bem como as alterações nos aspectos geomorfológicos são capazes de deflagrar processos geradores de deposições, especialmente em pontos mais baixos do relevo.

O estudo dos depósitos tecnogênicos tem possibilitado a reflexão acerca das relações existentes entre sociedade e natureza, em especial as modificações causadas pela sociedade nas dinâmicas naturais. Contudo, esta reflexão é ampla, abarcando diversos fatores, e ainda possui diferentes vieses para estudos futuros.

\section{AGRADECIMENTOS}

À Fundação de Amparo à Pesquisa do Estado de São Paulo, pelo apoio financeiro ao estudo desenvolvido por SILVA (2017) (Processo 2013/01302-0).

Aos editores da Revista do Instituto Geológico pelo convite para contribuirmos nesta edição dedicada ao Antropoceno no Estado de São Paulo. Aos revisores da Revista pelas sugestões apresentadas.

\section{REFERÊNCIAS}

ABREU, D.S. 1972. Formação histórica de uma cidade pioneira paulista: Presidente Prudente. Faculdade de Filosofia, Ciências e Letras, Universidade Estadual Paulista, Presidente Prudente, $339 \mathrm{p}$.

BRANNSTROM, C. 1998. After the Forest: Environment, Labor, and Agro-Commodity Production in Southeastern Brazil. University of Wisconsin-Madison, Madison, $\mathrm{PhD}$ Thesis, $771 \mathrm{p}$.

BRANNSTROM, C.; OLIVEIRA, A.M.S. 2000. Human modification of stream valleys in the Western Plateau of São Paulo, Brazil: implications for environmental narratives and management. Land Degradation \& Development, 11: 535-548. https://doi.org/10.1002/1099$145 \mathrm{X}(200011 / 12) 11: 6<535::$ A ID LDR412>3.0.CO;2-L

CASSETI, V. 1991. Ambiente e apropriação do relevo. Contexto, São Paulo, 147 p. 
CHEMEKOV, Y.F. 1983. Technogenic deposits In: INQUA, INQUA Congress, 11, Moscou, Anais, v. 3, p. 62.

CRUTZEN, P.J., STOERMER, E.F. 2000. The "Anthopocene". Global Change Newsletter, 41: 17-18.

DEAN, W. 2004. A ferro e fogo: a história e a devastação da Mata Atlântica brasileira. Cia. das Letras, São Paulo, 484 p.

DIAS, M.B.G. 2015. Depósitos Tecnogênicos na Região Noroeste de Goiânia (GO). Faculdade de Ciências e Tecnologia, Universidade Estadual Paulista, Presidente Prudente, Dissertação de Mestrado, 138 p.

FLORENCE, H. 1977. Viagem fluvial do Tietê ao Amazonas de 1825 a 1829 (tradução de Viscconde de Taunay). Cultrix/Edusp, São Paulo, 311 p.

GODOY, M.C.T.F.; SILVA, L.E.R.; SOUZA FILHO, A. 2002. O risco tecnogênico no planejamento físico territorial: exemplo de área de ampliação do distrito industrial de Presidente Prudente. Caderno Prudentino de Geografia, 24: 74-92.

MAZZINI, E.J. 1997. De lixo em lixo em Presidente Prudente (SP): novas áreas, velhos problemas. Faculdade de Ciências e Tecnologia, Universidade Estadual Paulista, Presidente Prudente, Monografia (Bacharelado), 96 p.

MONBEIG, P. 1984. Pioneiros e fazendeiros de São Paulo (tradução Ary França e Raul de Andrade e Silva). Hucitec/Polis, São Paulo, 392 p.

NUNES, J.O.R. 2002. Uma contribuição metodológica ao estudo da dinâmica da paisagem aplicada a escolha de áreas para construção de aterro sanitário em Presidente Prudente. Faculdade de Ciências e Tecnologia, Universidade Estadual Paulista, Presidente Prudente, Tese de Doutorado, $212 \mathrm{p}$.

NUNES, J.O.R; FREIRE, R.; PEREZ, I.U. 2006. Mapeamento Geomorfológico do perímetro urbano do município de Presidente Prudente-SP. In: UGB, SIMPÓSIO NACIONAL DE GEOMORFOLOGIA; REGIONAL CONFERENCE ON GEOMORFOLOGY, 6, Goiânia, Anais, 1: 1-11.
NUNES, J.O.R.; IMAI, N.N.; FUSHIMI, M. 2016. Aplicação de estudos geomorfológicos com base em técnicas de geoprocessamento na cidade de Presidente Prudente-SP, Brasil. In: C.E. Castro \& Y.A.G. Masullo (Org.). Gestão Ambiental: uma diversificada ferramenta na consolidação de paradigma ecológico inovador. São Luís, Editora UEMA, p. 31-58.

OLIVEIRA, A.M.S. 1994. Depósitos tecnogênicos e assoreamento de reservatórios: exemplo do reservatório de Capivara, Rio Paranapane$m a, S P / P R$. Faculdade de Filosofia, Letras e Ciências Humanas, Universidade de São Paulo, São Paulo, Tese de Doutorado, 221 p.

OLIVEIRA, A.M.S.; QUEIROZ NETO, J.P. 1994. Depósitos tecnogênicos induzidos pela erosão acelerada no Planalto Ocidental Paulista. Boletim Paulista de Geografia, 73: 91-123.

PEDRO, L.C. 2008. Ambiente e Apropriação dos Compartimentos Geomorfológicos do Conjunto Habitacional Jardim Humberto Salvador e do Condomínio Fechado Damha - Presidente Prudente-SP. Faculdade de Ciências e Tecnologia, Universidade Estadual Paulista, Presidente Prudente, Dissertação de Mestrado, $153 \mathrm{p}$.

PELOGGIA, A.U.G. 1996. Delineação e aprofundamento temático da geologia do tecnógeno do município de São Paulo: as conseqüências geológicas da ação do homem sobre a natureza e as determinações geológicas da ação humana em suas particularidades referentes à precária ocupação urbana. Instituto de Geociências, Universidade de São Paulo, São Paulo, Tese de Doutorado, 162 p.

PELOGGIA, A.U.G. 1998. O homem e o ambiente geológico: geologia, sociedade e ocupação urbana no município de São Paulo. Xamã, São Paulo, 271 p.

PELOGGIA, A.U.G. 2017. O que produzimos sob nossos pés? Uma revisão comparativa dos conceitos fundamentais referentes a solos e terrenos antropogênicos. Revista UNGGeociências, 16(1): 102-127.

PELOGGIA, A.U.G.; OLIVEIRA, A.M.S.; OLIVEIRA, A.A.; SILVA, E.C.N.; NUNES, J.O.R. 2014. Technogenic geodiversity: a proposal on the classification of artificial ground. Qua- 
ternary and Environmental Geosciences, 5(1): 28-40. http://dx.doi.org/10.5380/abequa. v5i1.34823

PICCHIA, M. 1927. São Paulo e o café. In: São Paulo e a sua evolução. Conferências realizadas no Centro Paulista em 1926. Typografia da Gazeta da Bolsa, Rio de Janeiro, n.p.

PIRES, K.L.N.; TOMA, R.; BACO, H.M.; NUNES, J.O.R. 2006. Análise dos depósitos tecnogênicos no Conjunto Habitacional Ana Jacinta e sua relação com os processos geomorfológicos. In: UGB, SIMPÓSIO NACIONAL DE GEOMORFOLOGIA; REGIONAL CONFERENCE ON GEOMORFOLOGY, 6, Goiânia, Anais, 1:1-10.

ROSS, J.L.S.; MOROZ, I.C. 1996. Mapa Geomorfológico do Estado de São Paulo. Revista do Departamento de Geografia, 10: 41-58.

SANTOS, M. 1996. Por uma geografia nova: da crítica da geografia a uma geografia crítica. Hucitec, São Paulo, 236 p.

SILVA, E.C.N. 2009. Formação de depósitos tecnogênicos nas proximidades do Conjunto Habitacional Jardim Humberto Salvador e Augusto de Paula na cidade de Presidente Prudente-SP. Faculdade de Ciências e Tecnologia, Universidade Estadual Paulista, Presidente Prudente, Monografia (Bacharelado), 89 p.
SILVA, E.C.N. 2012. Formação de depósitos tecnogênicos e relações com o uso e ocupação do solo no perímetro urbano de Presidente Prudente-SP. Faculdade de Ciências e Tecnologia, Universidade Estadual Paulista, Presidente Prudente, Dissertação de Mestrado, 183 p.

SILVA, E.C.N. 2017. Reconstituição Geomorfológica do Relevo Tecnogênico em Presidente Prudente$S P$. Faculdade de Ciências e Tecnologia, Universidade Estadual Paulista, Presidente Prudente, Tese de Doutorado, 246 p.

SILVA, L.J.P. 2011. Estudo sobre depósitos tecnogênicos no entorno da represa da SABESP em Presidente Prudente-SP. Faculdade de Ciências e Tecnologia, Universidade Estadual Paulista, Presidente Prudente, Monografia (Bacharelado), $73 \mathrm{p}$.

SMITH, N. 1988. Desenvolvimento desigual: natureza, capital e a produção de espaço (tradução de Eduardo de Almeida Navarro; coordenação editorial de Antonio Christofoletti). Bertrand Brasil, Rio de Janeiro, $250 \mathrm{p}$.

SPOSITO, E.S. (Coord.). 2003. Atlas da Inclusão/ Exclusão Social de Presidente Prudente. FCT, UNESP, SIMESSP, Presidente Prudente, 143 p.

TER-STEPANIAN, G. 1988. Beginning of the Technogene. Bulletin of the International Association of Engineering Geology, 38: 133142. https://doi.org/10.1007/BF02590457

\section{Endereço dos autores:}

Érika Cristina Nesta Silva - Alameda das Rosas, 2500, Condomínio Terra Nova, casa 565, CEP 78740620, Rondonópolis, MT. E-mail: erikanesta@yahoo.com.br

João Osvaldo Rodrigues Nunes e Marcel Bordin Galvão Dias - Faculdade de Ciências e Tecnologia, Universidade Estadual Paulista (UNESP), Rua Roberto Simonsen, 305, Centro Educacional, CEP 19060900, Presidente Prudente, SP.E-mails: joao.o.nunes@unesp.br, mbgdias@gmail.com

Antonio Manoel dos Santos Oliveira e Adriana Aparecida de Oliveira - Rodovia Oswaldo Cruz, 4700, Rua Brasil,60, Horto, CEP 11680-000, Ubatuba, SP.E-mails: amanoel2030@gmail.com, reinadriana@, gmail.com

Artigo submetido em 9 de janeiro de 2019, aceito em 30 de março de 2019. 